\title{
Intravenous vitamin C synergy with mEHT significantly improve QoL and prolong overal survival time in late stage NSCLC patients
}

\author{
Junwen Ou', Xinyu Zhu'1, Pengfei Chen', Yanping Du1, Clifford L.K. Pang',2
}

1. Cancer Center, Clifford Hospital, Guangzhou University of Chinese Medicine, Guangzhou, P.R. China

2. Hyperthermia Center, Clifford Hospital, Guangzhou University of Chinese Medicine, P.R. China

\section{BACKGROUND}

Intravenous vitamin C (IVC) and modulated electrohyperthermia $(\mathrm{mEHT})$ are widely used by integrative cancer practitioners for many years. ${ }^{1-3}$ However, there are no sufficient data in quality of life (QoL) ,clinical response and survival time of the above treatments in patients with stage III-IV Non-Small Cell Lung Cancer (NSCLC). Our phase I clinical trial proved that IVC simultaneously with mEHT were safe for NSCLC patients. ${ }^{4}$

\section{METHODS}

A randomised phase II controlled trial was performed to compare best supportive care (BSC) with and without IVC + mEHT concomitant treatment (In the active arm: patients were given $1 \mathrm{~g} / \mathrm{kg} \cdot \mathrm{d}$ simultaneously with mEHT, three times a week for 25 treatments in total)on tumour size, progression-free survival (PFS) and overall survival (OS) in advanced Chinese NSCLC patients.Subsequently, 97 patients were analysed at the data cut-off (1 May, 2019). Enhanced chest and abdomen CT scans, brain MRI and bone scans were carried out at baseline, and every 4 weeks for the first 12 weeks from the start of the study. Response measurements were carried out according to RECIST 1.1. 3 month disease control rate (DCR) was measured 3 months after the therapy and defined as the percentage of subjects with complete response (CR), partial response (PR) or stable disease (SD) at 3 months relative to all randomly assigned patients.

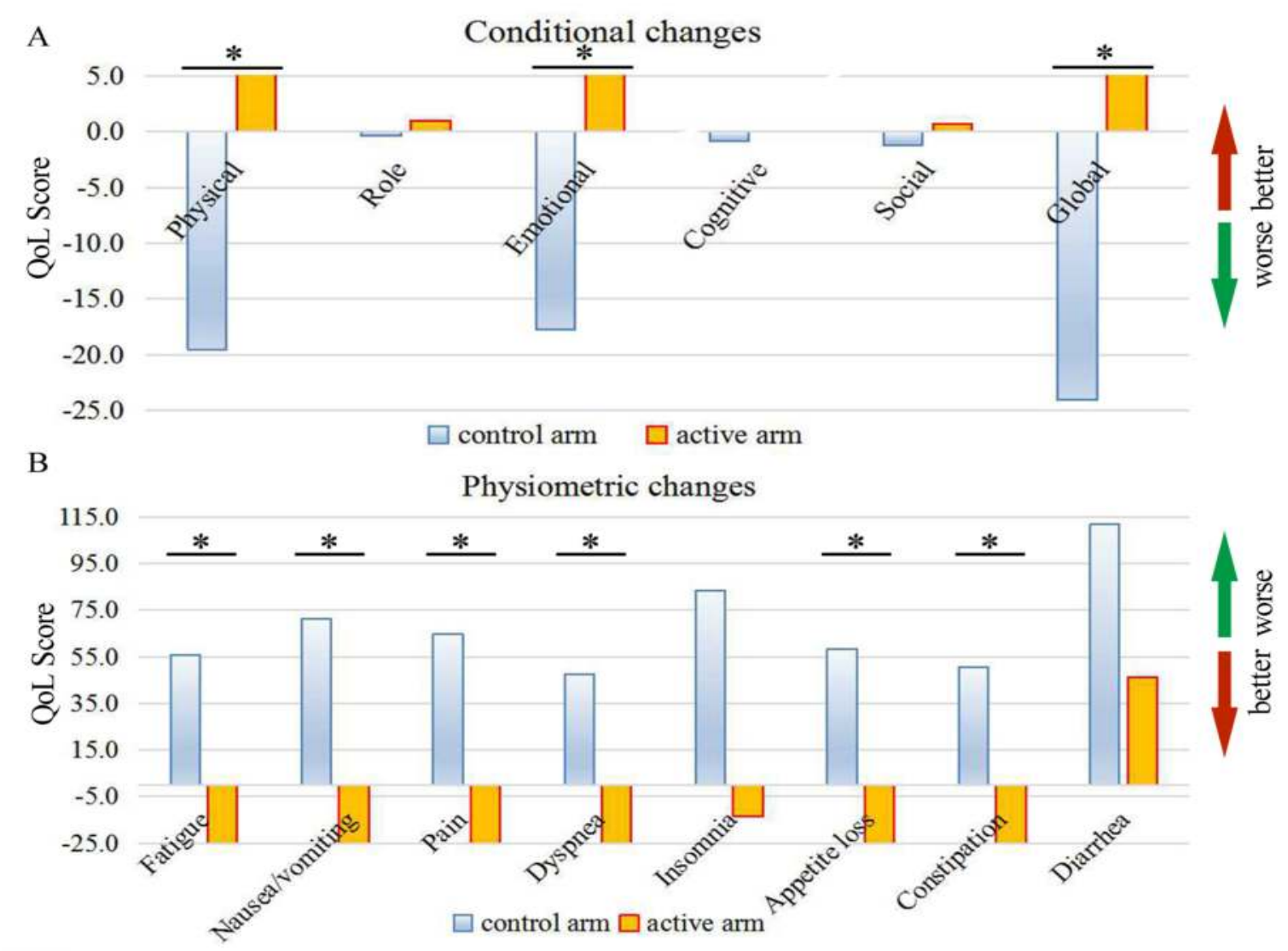

Figure 1 Function subscale(A) and psychometric parameters(B)

\section{Reference}

1. Welsh JL, Wagner BA, van't Erve TJ, Zehr PS, Berg DJ, Halfdanarson TR, et al. Pharmacological ascorbate with gemcitabine for the control of metastatic and node-positive pancreatic cancer (PACMAN): results from a phase I clinical trial. Cancer Chemother Pharmacol. 2013;71(3):765-75

2. Levine M, Wang Y, Padayatty SJ, Morrow J. A new recommended dietary allowance of vitamin C for healthy young women. Proc Natl Acad Sci U S A. 2001;98(17):9842-6. 3. Szasz A. Current status of oncothermia therapy for lung cancer. Korean J Thorac Cardiovasc Surg. 2014;47(2):77-93.

4. Ou J, Zhu X, Lu Y, Zhao C, Zhang H, Wang $X$, et al. The safety and pharmacokinetics of high dose intravenous ascorbic acid synergy with modulated electrohyperthermia in Chinese patients with stage III-IV non-small cell lung cancer. Eur J Pharm Sci. 2017:109:412-8.

\section{RESULTS}

After a median follow up of 24 months, both the PFS and OS were significantly improved by IVC + mEHT compared to control (PFS: 3 month vs. 1.85 months, $P<0.05$; OS: 10 months vs. 7.5 months, $\mathrm{P}<0.05)$. The average scores for the functioning scales increased continuously, so that the QoL improved in the active arm despite the advanced stage of the disease $(P<0.05) .3-$ month DCR after treatment was $42.9 \%$ in the active arm and $16.7 \%$ in the control arm $(P<0.05)$. Both interleukin-6 and $c-$ reactive protein were significantly decrease after treatments in active arm in comparison with control arm $(P<0.05)$. However, no significant differences were observed between parameters of adenocarcinoma and squamous cell carcinoma and between $\operatorname{EGFR}(+)$ and $\operatorname{EGFR}(-)$.

\section{CONCLUSIONS}

IVC + mEHT treatment significantly improves QoL, prolongs PFS and OS, and moderates cancer-related inflammation, and so is a feasible treatment for patients with advanced NSCLC. This trial is registered in ClinicalTrials.gov (ID: NCT02655913).

Table 1 Tumour size and DCR

\begin{tabular}{|c|c|c|c|}
\hline \multirow[t]{2}{*}{ Parameters } & \multicolumn{2}{|c|}{ Study arm } & \multirow[b]{2}{*}{$P$ value } \\
\hline & $\begin{array}{l}\text { Control } \\
(n=48)\end{array}$ & $\begin{array}{l}\text { Active } \\
(n=49)\end{array}$ & \\
\hline Number of death (\%) & $46(95.8)$ & $30(61.2)$ & \\
\hline PR (\%) & $0(0)$ & $7(14.3)$ & \\
\hline SD (\%) & $8(16.7)$ & $14(28.6)$ & \\
\hline PD (\%) & $40(83.3)$ & $28(57.1)$ & \\
\hline DCR $(\%)$ & 16.7 & 42.9 & 0.0073 \\
\hline
\end{tabular}
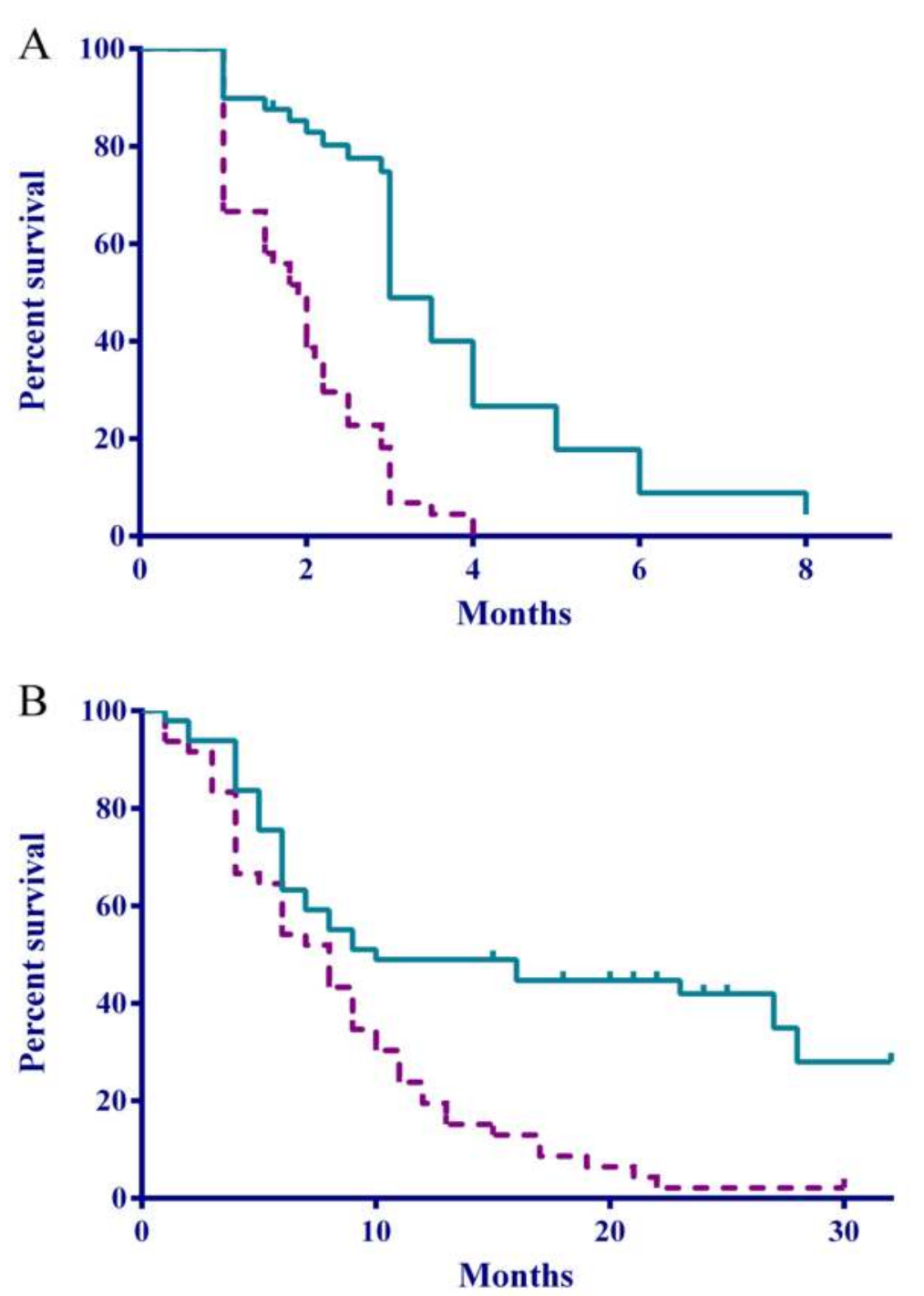

- PFS in Active

-- PFS in Control

- OS in Active -- OS in Control

Figure 2 Progression free survival time(A) and Overall survival time(B) 